\title{
Returns Relationship between Selected IT Stocks and the S\&P 500
}

\author{
C. Murugesan ${ }^{1}$, Dr. R. Perumalsamy ${ }^{2}$ \\ ${ }^{1}$ Senior Lecturer, Institute of Business Studies, Port Moresby, Papua New Guinea \\ ${ }^{2}$ Principal, Sri Subash College of Arts and Science, Pollachi, Tamil Nadu, India
}

\begin{abstract}
As the capital markets progress and magnify, more and more data is being formed daily. This explosion of data has made the flow of information much more efficient. As market participants act on this information flow, it drives market returns to more efficient values. Predicting daily behavior of stock market is a serious challenge for investors and corporate stockholders and it can help them to invest with more confident by taking risks and fluctuations into consideration. This paper seeks to examine a number of different forecasting techniques to predict future stock returns based on the past returns, by applying regression for predicting returns behavior. In this study top five American Information Technology companies stocks were taken, the result of the techniques which are discussed in this study helps investor to forecast the returns of securities and they can make investment decisions consequently.
\end{abstract}

Keywords: Securities, Returns, Past Price, Prediction Return, Chart, Return Behavior

\section{Introduction}

The capital markets serve as a place for investors to efficiently distribute capital to entrepreneurs and businesses so that they can effectively provide their services to society. In order for this process to work best, markets need to be both liquid and efficient. This means that an investor can buy or sell a reasonable quantity at a fair price. Long-term investors are not the only participants keeping the market working efficiently. There are two main schools of thought in the financial markets, technical analysis and fundamental analysis. Fundamental analysis attempts to determine a stock's return by focusing on underlying factors that affect a company's actual business and its future prospects. Fundamental analysis can be performed on industries or the company as a whole, Fundamental information like financial and non-financial aspects of the company or technical information which ignores fundamentals. The technical analyst assumes that it is 90 percent psychological and 10 percent logical. Technical analysis is a method of evaluating securities by analyzing statistics generated by market activity, such as past price, returns and volume. But instead use chart and other tools to identify pattern that can suggest future activity. Technical analysis on the other hand, looks at the returns movement of a stock and use this data to predict its future return movements. Time frame in which technical analysis is applied many range from intraday 5 minute, 10 minute, 15 minutes, 30 minutes or hourly, daily, weekly or monthly returns data to many years.

\section{Assumptions of Technical Analysis}

1. Market Fluctuations Discount Everything else.

Technical analysts believe that changes in the price of a security and how well it trades in the market embody all available information about that security from everyone involved with it and therefore represents the fair value of that security. Sudden changes in how a stock trades often precedes major news about the company that issued the stock. Technical analysts don't concern themselves with the price-to-earnings ratio, shareholder equity, return on equity or other factors that fundamental analysts do.

\section{Price Movements can often be Charted and Predicted.}

Technical analysts acknowledge that there are periods when prices move randomly, but there are also times when they move in an identifiable trend. Once a trend is identified, it is possible to make money from it, either by buying low and selling high during an upward trend (bull market) or by selling short during a downward trend (bear market). By adjusting the length of time the market is being analyzed, it is possible to spot both short- and long-term trends.

\section{History Repeats Itself.}

People don't change their motivations overnight; therefore, traders will react the same way to conditions as they did in the past when those conditions repeat themselves. Because people react the same way, technical analysts can use the knowledge of how other traders reacted in the past to profit each time those conditions repeat them.

\section{Objectives}

1) To study the relevance of technical analysis in American Capital Market

2) To analyze the performance of select companies in American Stock Market and to predict the future trends in the share returns through technical analysis

3) To find out return for selected securities

4) Technical analysis on selected stock and interpret on returns movement

5) To suggesting the investors in making investment decision in selected stock.

\section{Research Methodology}

The technical analysis, secondary data the monthly share return movements of the selected companies in NYSE / NASDAQ were absorbed for the 3 years i.e. Jan 2013 to Dec 2015. The closing prices of share prices were taken and the future returns movement was analyzed using tools. Data were collected from trading of equity market in NYSE / 


\section{International Journal of Science and Research (IJSR) \\ ISSN (Online): 2319-7064 \\ Index Copernicus Value (2013): 6.14 | Impact Factor (2015): 6.391}

NASDAQ, various books, Journals, Magazines and Website. All the listed companies in the New York Stock Exchange companies which are actively traded in NYSE / NASDAQ were taken on stratified sampling basis for the study.

The selected companies are given below:

1) CA Inc. (CA)

2) SAP SE (SAP)

3) International Business Machines Corporation (IBM)

4) Microsoft Corporation (MSFT)

5) Oracle Corporation (ORCL)

Time Period of the Study: The period of three years form Jan. 2013 to Dec. 2015 have been taken to carry out the present study.

\section{Secondary Data}

The secondary data have been collected from the stock market indices, web sites and journals.

\section{Limitations}

1) Technical analysis only for three years is undertaken; from this data we cannot predict returns accurately.

2) For doing this analysis the researchers has taken into consider only limited parameters. These parameters may not enough to predict the future return movements.

3) This study can be used only for short term decision making.

\begin{tabular}{|c|c|c|c|c|c|c|c|}
\hline \multicolumn{8}{|c|}{ Returns of S\&P 500 and Selected IT Companies Equity (2013-15) } \\
\hline Date & S\&P 500 & S\&P 500 Ret. & CA Ret. & $\begin{array}{c}\text { IBM } \\
\text { Ret. } \\
\end{array}$ & MSFT Ret. & Oracle Ret. & SAP Ret. \\
\hline $12 / 1 / 2015$ & 2043.94 & $1.75 \%$ & $1.60 \%$ & $-1.29 \%$ & $2.08 \%$ & $-6.26 \%$ & $0.13 \%$ \\
\hline $11 / 2 / 2015$ & 2080.41 & $0.05 \%$ & $2.40 \%$ & $0.46 \%$ & $3.94 \%$ & $0.33 \%$ & $0.37 \%$ \\
\hline $10 / 1 / 2015$ & 2079.36 & $8.30 \%$ & $1.50 \%$ & $-3.37 \%$ & $18.93 \%$ & $7.96 \%$ & $21.48 \%$ \\
\hline $9 / 1 / 2015$ & 1920.03 & $2.64 \%$ & $0.04 \%$ & $-1.97 \%$ & $1.70 \%$ & $-2.62 \%$ & $-3.67 \%$ \\
\hline $8 / 3 / 2015$ & 1972.18 & $6.26 \%$ & $5.46 \%$ & $-7.95 \%$ & $-6.19 \%$ & $-7.14 \%$ & $-6.15 \%$ \\
\hline $7 / 1 / 2015$ & 2103.84 & $1.97 \%$ & $0.51 \%$ & $-0.41 \%$ & $5.78 \%$ & $-0.52 \%$ & $2.05 \%$ \\
\hline $6 / 1 / 2015$ & 2063.11 & $2.10 \%$ & $3.81 \%$ & $-4.12 \%$ & $-5.78 \%$ & $-7.34 \%$ & $-4.97 \%$ \\
\hline $5 / 1 / 2015$ & 2107.39 & $1.05 \%$ & $3.38 \%$ & $-0.21 \%$ & $-3.03 \%$ & $-0.30 \%$ & $-0.83 \%$ \\
\hline $4 / 1 / 2015$ & 2085.51 & $0.85 \%$ & $2.58 \%$ & $6.72 \%$ & $19.63 \%$ & $1.44 \%$ & $4.88 \%$ \\
\hline $3 / 2 / 2015$ & 2067.89 & $1.74 \%$ & $0.28 \%$ & $-0.89 \%$ & $-7.27 \%$ & $-1.53 \%$ & $2.82 \%$ \\
\hline $2 / 2 / 2015$ & 2104.5 & $5.49 \%$ & $8.16 \%$ & $6.37 \%$ & $9.31 \%$ & $4.61 \%$ & $7.39 \%$ \\
\hline $1 / 2 / 2015$ & 1994.99 & $3.10 \%$ & $0.49 \%$ & $-4.44 \%$ & $13.02 \%$ & $-6.60 \%$ & $-6.16 \%$ \\
\hline $12 / 1 / 2014$ & 2058.9 & $0.42 \%$ & $2.25 \%$ & $-1.07 \%$ & $-2.84 \%$ & $6.04 \%$ & $-0.95 \%$ \\
\hline $11 / 3 / 2014$ & 2067.56 & $2.45 \%$ & $8.09 \%$ & $-0.68 \%$ & $2.47 \%$ & $8.60 \%$ & $3.21 \%$ \\
\hline $10 / 1 / 2014$ & 2018.05 & $2.32 \%$ & $4.01 \%$ & $13.40 \%$ & $1.27 \%$ & $2.33 \%$ & $-5.58 \%$ \\
\hline $9 / 2 / 2014$ & 1972.29 & $1.55 \%$ & $1.06 \%$ & $-1.28 \%$ & $2.05 \%$ & $-7.83 \%$ & $-7.40 \%$ \\
\hline $8 / 1 / 2014$ & 2003.37 & $3.77 \%$ & $1.35 \%$ & $0.92 \%$ & $5.92 \%$ & $2.82 \%$ & $-0.71 \%$ \\
\hline $7 / 1 / 2014$ & 1930.67 & $1.51 \%$ & $0.49 \%$ & $5.74 \%$ & $3.50 \%$ & $-0.06 \%$ & $1.94 \%$ \\
\hline $6 / 2 / 2014$ & 1960.23 & $1.91 \%$ & $0.17 \%$ & $-1.68 \%$ & $1.86 \%$ & $-3.55 \%$ & $0.65 \%$ \\
\hline $5 / 1 / 2014$ & 1923.57 & $2.10 \%$ & $3.99 \%$ & $-5.62 \%$ & $2.05 \%$ & $2.79 \%$ & $-3.79 \%$ \\
\hline $4 / 1 / 2014$ & 1883.95 & $0.62 \%$ & $2.71 \%$ & $2.07 \%$ & $-1.44 \%$ & $0.22 \%$ & $-0.39 \%$ \\
\hline $3 / 3 / 2014$ & 1872.34 & $0.69 \%$ & $7.52 \%$ & $3.95 \%$ & $7.00 \%$ & $4.60 \%$ & $1.27 \%$ \\
\hline $2 / 3 / 2014$ & 1859.45 & $4.31 \%$ & $5.19 \%$ & $5.38 \%$ & $2.00 \%$ & $5.99 \%$ & $5.06 \%$ \\
\hline $1 / 2 / 2014$ & 1782.59 & $3.56 \%$ & $4.64 \%$ & $-5.81 \%$ & $1.15 \%$ & $-3.25 \%$ & $12.30 \%$ \\
\hline $12 / 2 / 2013$ & 1848.36 & $2.36 \%$ & $1.97 \%$ & $4.39 \%$ & $-1.89 \%$ & $8.42 \%$ & $5.34 \%$ \\
\hline $11 / 1 / 2013$ & 1805.81 & $2.80 \%$ & $4.70 \%$ & $0.80 \%$ & $8.50 \%$ & $5.34 \%$ & $5.58 \%$ \\
\hline $10 / 1 / 2013$ & 1756.54 & $4.46 \%$ & $7.04 \%$ & $-3.22 \%$ & $6.40 \%$ & $1.36 \%$ & $5.99 \%$ \\
\hline $9 / 3 / 2013$ & 1681.55 & $2.97 \%$ & $1.44 \%$ & $1.60 \%$ & $-0.36 \%$ & $4.11 \%$ & $0.14 \%$ \\
\hline $8 / 1 / 2013$ & 1632.97 & $3.13 \%$ & $0.83 \%$ & $-6.08 \%$ & $5.64 \%$ & $-1.51 \%$ & $1.28 \%$ \\
\hline $7 / 1 / 2013$ & 1685.73 & $4.95 \%$ & $3.91 \%$ & $2.06 \%$ & $-7.82 \%$ & $5.74 \%$ & $0.08 \%$ \\
\hline $6 / 3 / 2013$ & 1606.28 & $1.50 \%$ & $4.76 \%$ & $-8.13 \%$ & $-1.03 \%$ & $-9.09 \%$ & $-0.83 \%$ \\
\hline $5 / 1 / 2013$ & 1630.74 & $2.08 \%$ & $2.22 \%$ & $3.19 \%$ & $6.18 \%$ & $3.05 \%$ & $-6.66 \%$ \\
\hline $4 / 1 / 2013$ & 1597.57 & $1.81 \%$ & $7.11 \%$ & $-5.04 \%$ & $15.69 \%$ & $1.39 \%$ & $-0.86 \%$ \\
\hline $3 / 1 / 2013$ & 1569.19 & $3.60 \%$ & $2.73 \%$ & $6.21 \%$ & $2.91 \%$ & $-5.58 \%$ & $2.99 \%$ \\
\hline $2 / 1 / 2013$ & 1514.68 & $1.11 \%$ & $0.25 \%$ & $-0.69 \%$ & $2.11 \%$ & $-3.58 \%$ & $-4.66 \%$ \\
\hline $1 / 2 / 2013$ & 1498.11 & & & & & & \\
\hline
\end{tabular}

\section{CA Technologies}

Formerly known as Computer Associates International, Inc. and CA, Inc., is one of the largest independent software corporations in the world. CA for short, is an American, multinational, publicly held company headquartered in New York City. The company creates systems software (and previously applications software) that runs in mainframe, distributed computing, virtual machine and cloud computing environments.
Although the company once sold anti-virus and Internet security commercial software programs for personal computers during its venture into the business-to-consumer ("B2C") market, it remains primarily known for its businessto-business ("B2B") mainframe and distributed (client/server, etc.) information technology ("IT") infrastructure applications since the spin-off of their security products into Total Defense. CA Technologies claims that its computer software products are used by "a majority of 


\section{International Journal of Science and Research (IJSR) \\ ISSN (Online): 2319-7064}

Index Copernicus Value (2013): 6.14 | Impact Factor (2015): 6.391

the Fortune Global 500 companies, government organizations, educational institutions, and thousands of other companies in diverse industries worldwide."

CA Technologies posted $\$ 4.4$ billion in revenue for fiscal year 2014 (ending March 31, 2014) and maintains offices in more than 40 countries. The company employs approximately 12,700 people (March 31, 2014). CA holds more than 950 patents worldwide, and has more than 900 patent applications pending.
Table 1: Table Showing Correlation of CA Inc.

\begin{tabular}{|c|c|c|c|}
\hline Particulars & S\&P 500 & & CA Inc. \\
\hline Average & $0.94 \%$ & & $0.77 \%$ \\
\hline Variance & 0.00089 & & 0.001476 \\
\hline Standard Deviation & $2.98 \%$ & & $3.84 \%$ \\
\hline Covariance & & 0.000602 & \\
\hline Correlation & & $52.57 \%$ & \\
\hline
\end{tabular}

From the Table 1, it could be concluded that the CA Inc. company's security are more volatility than the market returns. Moreover it has less volatility when compared to other companies taken for this study. Also coefficient is a statistical measure that reflects the correlation between securities and market or between two securities. Other words, this statistics tells us how closely one security is related to the others. Calculated correlation coefficient between S\&P 500 and CA Inc. has positive and moves in the same direction, but it is weak linear relationship.

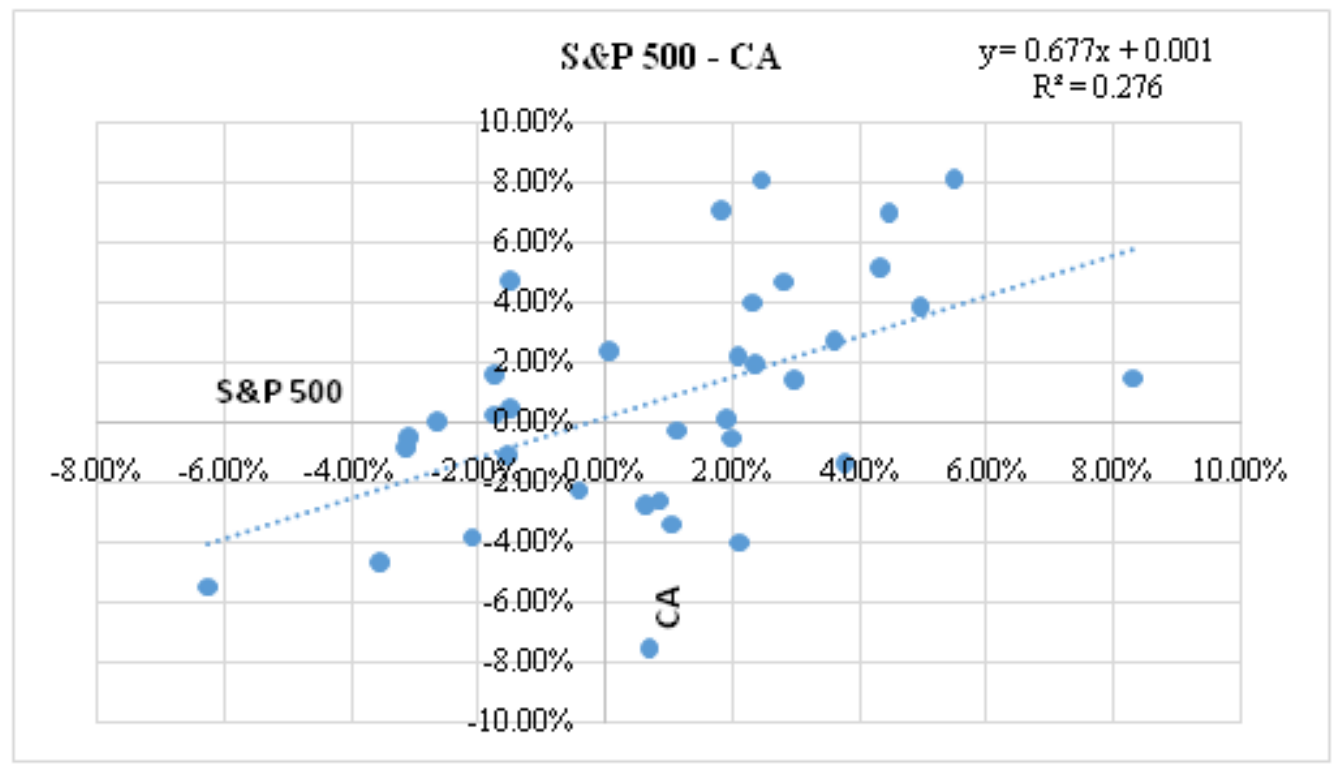

Chart 1: Chart Showing Regression of S\&P and CA

From the above Regression line that kind of gives us a sense for how CA Inc. varies with S\&P 500 returns, Just visually there is a slope upward, so that tells us that as S\&P 500 returns increase along the ' $\mathrm{X}$ ' axis and $\mathrm{CA}$ Inc. returns also tent to increase along the ' $\mathrm{Y}$ ' axis. Huge variation between the plots in the graph that some points are away and other points are really close to the line, it tells us that CA Inc. varies for reason other than just S\&P 500's variation. The equation tells us here that for every increase of $1 \%$ point of $\mathrm{S} \& \mathrm{P} 500$ returns, there is a $0.677 \%$ increase in CA Inc. returns. If S\&P 500 were 0 , stayed completely flat between any two months then CA Inc. gets positive 0.0014 , and would increase by $0.14 \%$.

Finally $\mathrm{R}^{2} 0.2763$, about $27 \%$ of the variation in CA Inc. is explained by S\&P 500. The fact that CA Inc. stock is fluctuating is partly explained because the S\&P 500 itself is fluctuating and partly because there may be specific things happening within CA Inc. and other factor.

\section{International Business Corporation (IBM) \\ Machines}

An American multinational technology and consulting corporation, with corporate headquarters in Armonk, New York. IBM manufactures and markets computer hardware, middleware and software and offers infrastructure, hosting and consulting services in areas ranging from mainframe computers to nanotechnology.

The company originated in 1911 as the ComputingTabulating-Recording Company (CTR) through the consolidation of The Tabulating Machine Company, the International Time Recording Company, the Computing Scale Company and the Bundy Manufacturing Company. CTR was renamed "International Business Machines" in 1924, Securities analysts nicknamed the company Big Blue for its size and common use of the color in products, packaging and its logo. 


\section{International Journal of Science and Research (IJSR) \\ ISSN (Online): 2319-7064 \\ Index Copernicus Value (2013): 6.14 | Impact Factor (2015): 6.391}

In 2012, Fortune ranked IBM the second largest U.S. firm in terms of number of employees $(435,000$ worldwide), the fourth largest in terms of market capitalization, the ninth most profitable, and the nineteenth largest firm in terms of revenue. Globally, the company was ranked the 31 st largest in terms of revenue by Forbes for 2011. Other rankings for 2011/2012 include No. 1 company for leaders (Fortune), green company in the United States (Newsweek), No. 2 best global brand, most respected company (Barron's), IBM has 12 research laboratories worldwide, bundled into IBM Research. As of 2013 the company held the record for most patents generated by a business for 22 consecutive years. Its employees have garnered five Nobel Prizes, six Turing Awards, ten National Medals of Technology and five National Medals of Science.
Table 2: Table Showing Correlation of IBM

\begin{tabular}{|c|c|c|c|}
\hline Particulars & S\&P 500 & & IBM Ret. \\
\hline Average & $0.94 \%$ & & $-0.79 \%$ \\
\hline Variance & 0.00089 & & 0.002087 \\
\hline Standard Deviation & $2.98 \%$ & & $4.57 \%$ \\
\hline Covariance & & 0.000513 & \\
\hline Correlation & & $37.64 \%$ & \\
\hline
\end{tabular}

From the Table 2, it could be concluded that the IBM Company's security are more volatility than the market returns and calculated correlation coefficient between S\&P 500 and IBM has positive and moves in the same direction, but it also has weak linear relationship.

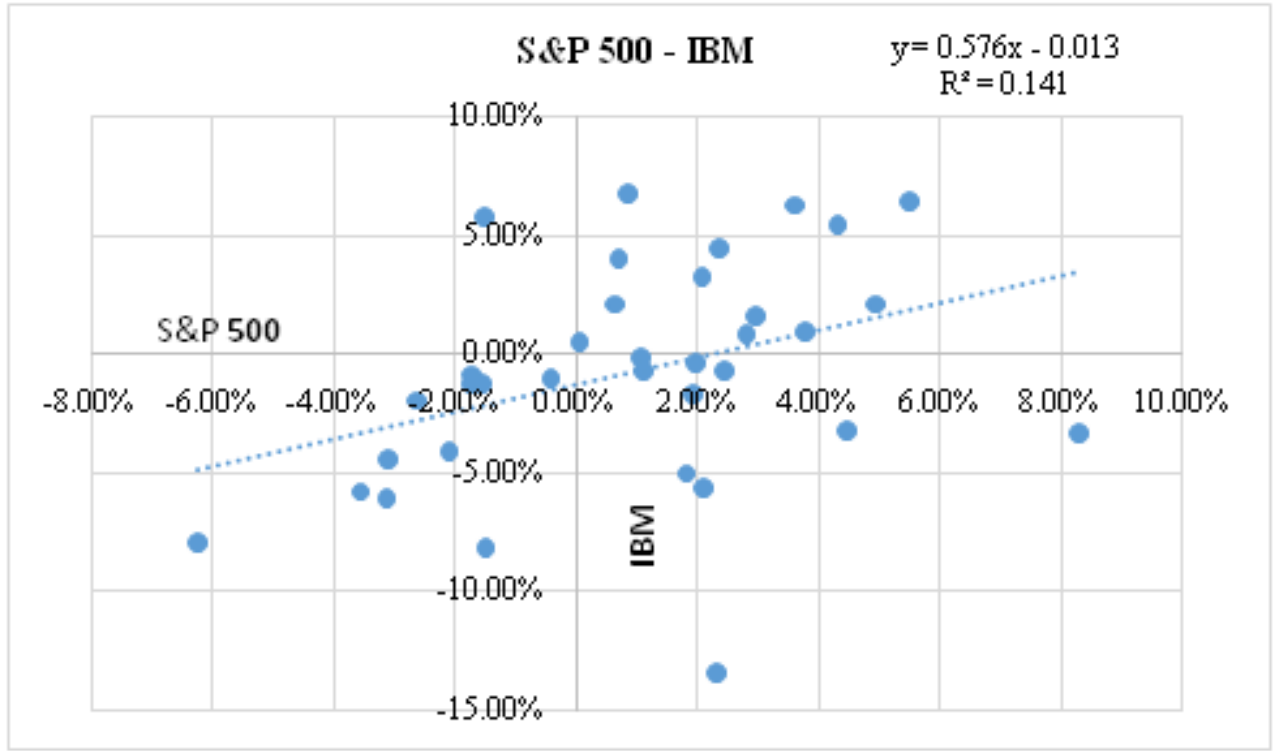

Chart 2: Chart Showing Regression of S\&P and IBM

From the above Regression line that kind of gives us a sense for how IBM varies with S\&P 500 returns, Just visually there is a slope upward, so that tells us that as S\&P 500 returns increase along the ' $\mathrm{X}$ ' axis and IBM. returns also tent to increase along the ' $\mathrm{Y}$ ' axis. Huge variation between the plots in the graph that some points are away and other points are really close to the line, it tells us that IBM varies for reason other than just S\&P 500's variation. The equation tells us here that for every increase of $1 \%$ point of S\&P 500 returns, there is a $0.5762 \%$ increase in IBM returns. If S\&P 500 were 0 , stayed completely flat between any two months thenIMB gets negative $0.0132 \%$, and stock would decline by $1.32 \%$.

Finally $\mathrm{R}^{2} 0.1416$, about $14 \%$ of the variation in IBM explained by S\&P 500. The fact that IBM stock is fluctuating is partly explained because the S\&P 500 itself is fluctuating and partly because there may be specific things happening within IBM and other factor.

Microsoft Corporation (commonly referred to as Microsoft)

Microsoft(MSFT)is an American multinationaltechnology company headquartered in Redmond, Washington, that develops, manufactures, licenses, supports and sells computer software, consumer electronics and personal computers and services. Its best known software products are the Microsoft Windows line of operating systems, Microsoft Office suite, and Internet Explorer and Edgeweb browsers. Its flagship hardware products are the Xbox game consoles and the Microsoft Surface tablet lineup. It is the world's largest software maker by revenue, and one of the world's most valuable companies.

Microsoft was founded by Paul Allen and Bill Gates on April 4, 1975, to develop and sell BASICinterpreters for Altair 8800. It rose to dominate the personal computeroperating system market with MS-DOS in the mid1980s, followed by Microsoft Windows. Since the 1990s, it has increasingly diversified from the operating system market and has made a number of corporate acquisitions. In May 2011, Microsoft acquired Skype Technologies for $\$ 8.5$ billion in its largest acquisition to date, and in June 2016 announced plans to acquire LinkedIn for \$26.2 billion.

As of 2015, Microsoft is market dominant in both the IBM PC-compatible operating system (while it lost the majority of the overall operating system market to Android) and office software suite markets (the latter with Microsoft Office). The company also produces a wide range of other software for desktops and servers, and is active in areas 


\section{International Journal of Science and Research (IJSR) \\ ISSN (Online): 2319-7064}

Index Copernicus Value (2013): 6.14 | Impact Factor (2015): 6.391

including Internet search (with Bing), the video game industry, digital services and mobile phones.

Table 3: Table Showing Correlation of MSFT

\begin{tabular}{|c|c|c|c|}
\hline Particulars & S\&P 500 & & MSFT \\
\hline Average & $0.94 \%$ & & $2.50 \%$ \\
\hline Variance & 0.00089 & & 0.004603 \\
\hline Standard Deviation & $2.98 \%$ & & $6.88 \%$ \\
\hline Covariance & & 0.000954 & \\
\hline Correlation & & $47.13 \%$ & \\
\hline
\end{tabular}

From the Table 3, shows that the MSFT Company's security are more volatility than the market returns and calculated correlation coefficient between S\&P 500 and MSFT has positive and moves in the same direction, but it has weak moderate linear relationship.

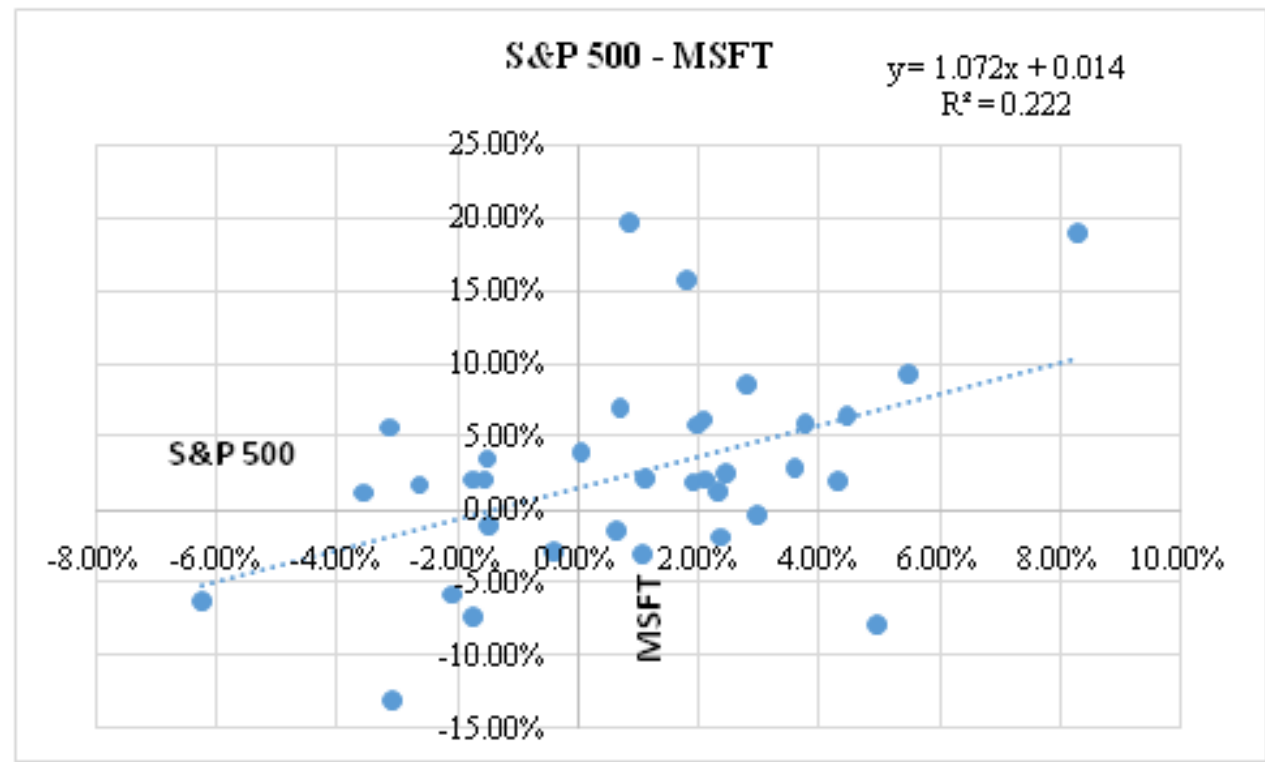

Chart 3: Chart Showing Regression of S\&P and MSFT

From the above Regression line that kind of gives us a sense for how MSFT varies with S\&P 500 returns, Just visually there is a slope upward, so that tells us that as S\&P 500 returns increase along the ' $\mathrm{X}$ ' axis and MSFT returns also tent to increase along the ' $\mathrm{Y}$ ' axis. Huge variation between the plots in the graph that some points are away and other points are really close to the line, it tells us that MSFT varies for reason other than just S\&P 500's variation. The equation tells us here that for every increase of $1 \%$ point of S\&P 500 returns, there is a $1.0721 \%$ increase in MSFT returns. If S\&P 500 were 0 ,stayed completely flat between any two months then MSFT gets positive $0.0149 \%$, and would increase by $1.49 \%$.

Finally $\mathrm{R}^{2} 0.2221$, about $22 \%$ of the variation in MSFT explained by S\&P 500. The fact that MSFT stock is fluctuating is partly explained because the S\&P 500 itself is fluctuating and partly because there may be specific things happening within MSFT and other factor.

\section{Oracle Corporation}

Oracle Corporation is an American multinational computer technology corporation, headquartered in Redwood City, California. The company primarily specializes in developing and marketing database software and technology, cloud engineered systems and enterprise software products particularly its own brands of database management systems. In 2011 Oracle was the second-largest software maker by revenue, after Microsoft.

The company also develops and builds tools for database development and systems of middle-tier software, enterprise resource planning (ERP) software, customer relationship management (CRM) software and supply chain management (SCM) software

Table 4: Table Showing Correlation of Oracle

\begin{tabular}{|c|c|c|c|}
\hline Particulars & S\&P 500 & & Oracle \\
\hline Average & $0.94 \%$ & & $0.30 \%$ \\
\hline Variance & 0.00089 & & 0.002415 \\
\hline Standard Deviation & $2.98 \%$ & & $4.91 \%$ \\
\hline Covariance & & 0.001011 & \\
\hline Correlation & & $69.00 \%$ & \\
\hline
\end{tabular}

From the Table 4, it could be concluded that the Oracle security are more volatility than the market returns and calculated correlation coefficient between S\&P 500 and Oracle has positive and moves in the same direction, but it also has strong linear relationship 
International Journal of Science and Research (IJSR)

ISSN (Online): 2319-7064

Index Copernicus Value (2013): 6.14 | Impact Factor (2015): 6.391

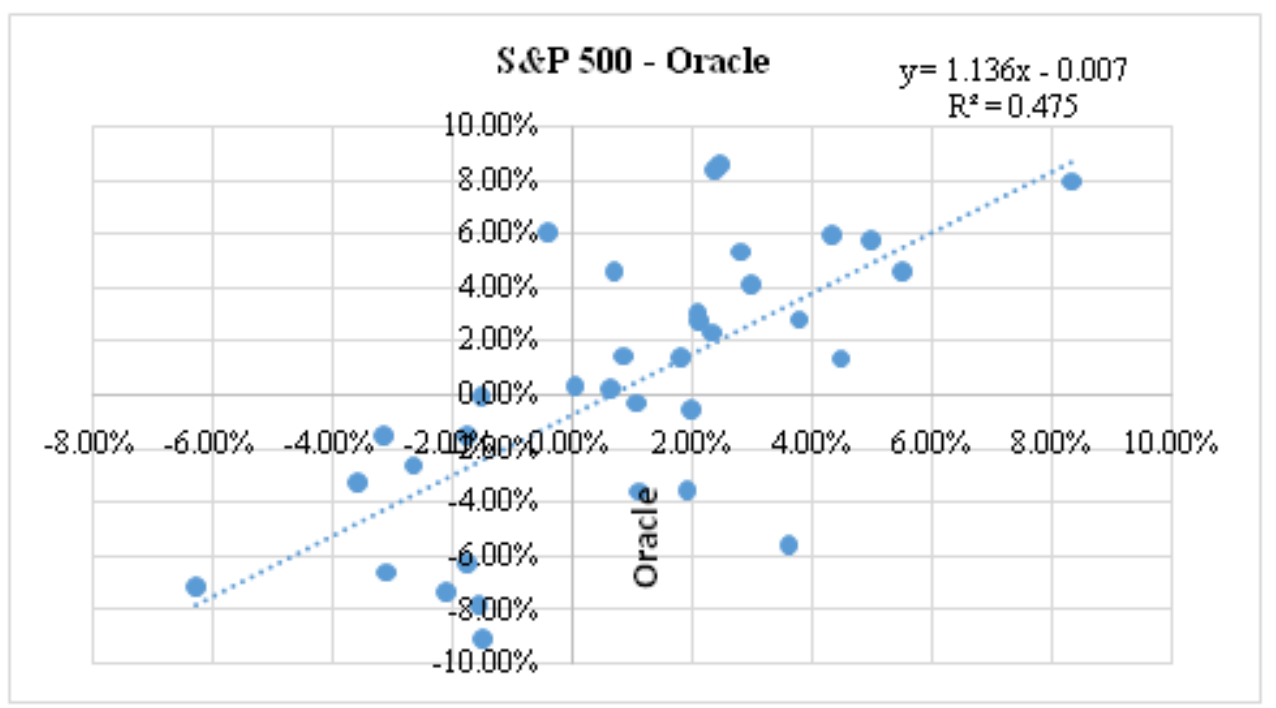

Chart 4: Chart Showing Regression of S\&P and Oracle

From the above Regression line that kind of gives us a sense for how Oracle varies with S\&P 500 returns, Just visually there is a slope upward, so that tells us that as S\&P 500 returns increase along the ' $\mathrm{X}$ ' axis and Oracle returns also tent to increase along the ' $\mathrm{Y}$ ' axis. Huge variation between the plots in the graph that some points are away and other points are really close to the line, it tells us that Oracle varies for reason other than just S\&P 500's variation. The equation tells us here that for every increase of $1 \%$ point of S\&P 500 returns, there is a $1.1361 \%$ increase in Oracle returns. If S\&P 500 were 0 ,stayed completely flat between any two months then Oracle gets negative $0.0077 \%$, would decline byjust $0.77 \%$.

Finally $\mathrm{R}^{2} 0.4758$, about $47 \%$ of the variation in Oracleexplained by S\&P 500. The fact that Oracle stock is fluctuating is partly explained because the $\mathrm{S} \& \mathrm{P} 500$ itself is fluctuating and partly because there may be specific things happening within Oracle and other factor.

\section{SAP SE}

SAP SE(System analyses and Programme networking; Systems, Applications \& Products in Data Processing) is a German multinationalsoftware corporation that makes enterprise software to manage business operations and customer relations. SAP is headquartered in Walldorf, Baden-Württemberg, Germany, with regional offices in 130 countries. The company has over 293,500 customers in 190 countries. The company is a component of the Euro Stoxx 50stock market index. In 1976, SAP GmbH was founded, and moved its headquarters the following year to Walldorf, Germany. Three years later, in 1979, SAP launched SAP $\mathrm{R} / 2$, expanding the capabilities of the system to other areas, such as material management and production planning. In 1981, SAP brought a re-designed product to market. However, SAP R/2 did not improve until the period between 1985 and 1990. SAP released the new SAP R/3 in 1992. SAP developed and released several versions of $\mathrm{R} / 3$ through 1995. By the mid-1990s, SAP followed the trend from mainframe computing to client/server architectures. The development of SAP's internet strategy with mySAP.com redesigned the concept of business processes. SAP was awarded Industry Week's Best Managed Companies in 1999.

Table 5: Table Showing Correlation of SAP

\begin{tabular}{|c|c|c|c|}
\hline Particulars & S\&P 500 & & SAP \\
\hline Average & $0.94 \%$ & & $0.19 \%$ \\
\hline Variance & 0.00089 & & 0.00324 \\
\hline Standard Deviation & $3.03 \%$ & & $5.69 \%$ \\
\hline Covariance & & 0.001133 & \\
\hline Correlation & & $66.71 \%$ & \\
\hline
\end{tabular}

From the Table 5, it could be concluded that the SAP's security are more volatility than the market returns and correlation coefficient between S\&P 500 and SAP has positive and moves in the same direction, but it also has Strong linear relationship. 
International Journal of Science and Research (IJSR)

ISSN (Online): 2319-7064

Index Copernicus Value (2013): 6.14 | Impact Factor (2015): 6.391

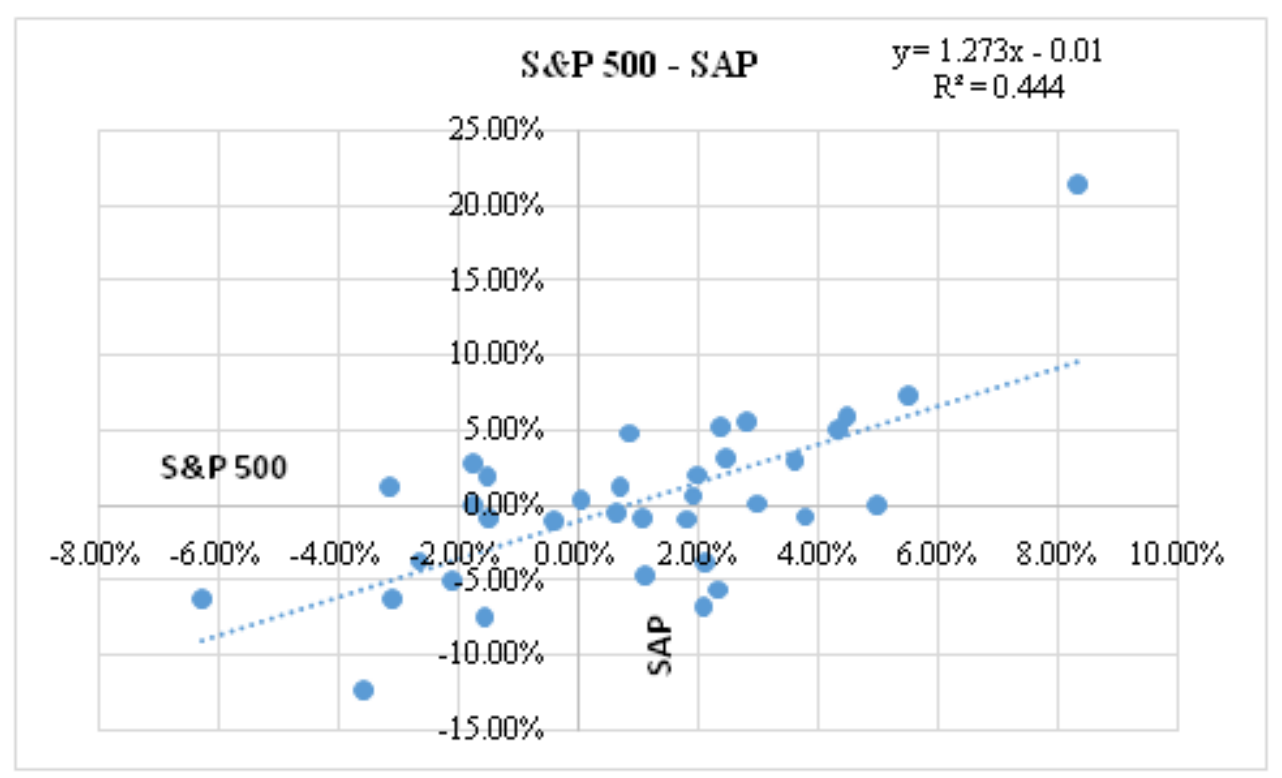

Cart No. 5: Chart Showing Regression of S\&P and ASP

From the above Regression line that kind of gives us a sense for how SAP varies with S\&P 500 returns, Just visually there is a slope upward, so that tells us that as S\&P 500 returns increase along the ' $\mathrm{X}$ ' axis and SAP returns also tent to increase along the ' $\mathrm{Y}$ ' axis. Huge variation between the plots in the graph that some points are away and other points are really close to the line, it tells us that SAP varies for reason other than just S\&P 500's variation. The equation tells us here that for every increase of $1 \%$ point of S\&P 500 returns which is $\mathrm{X}$, there is a $1.2731 \%$ increase in SAP returns. If S\&P 500 were 0 ,stayed completely flat between any two monthsSAP gets negative 0.01 , would decline by $1 \%$. Finally $\mathrm{R}^{2} 0.4449$, about $44 \%$ of the variation in SAPexplained by S\&P 500. The fact that SAP stock is fluctuating is partly explained because the S\&P 500 itself is fluctuating and partly because there may be specific things happening within SAP and other factor.

\section{Conclusion}

Technical analysis is a technique which gives an awareness about future share returns and prices of selected companies in which investor invest. From the above study investor can identify the securities which are giving more returns for their investment based on the past returns. Also the study revealed that some of the companies are more volatile and some are less than the market returns, stock returns moved towards and contradictory to market returns, also learnt that weak strong linear relationship with market index. By using the technical indicators the future market of securities would be known in which to invest. The more accurate prediction of stock returns of selected companies the investor to carry out fundamental analysis of stock, they can predict of future trend of stock returns and price. On the basis of prediction of five companies (i.e. CA Inc. IBM, MSFT, ORACLE and SAP) different pattern of stock returns of these companies give an idea of future trend of these companies could be analyzed with the right technical analysis tools, technical analysis of utmost importance to predict trend of short and medium term returns movement and help the investors to select the right stock to invest in the remunerative one. The technician also required a fundamental knowledge, which would give a clear idea about the investment decision. Both Technical and Fundamental analysis helps in investment decision in the stock market and predict the future trend of the selected companies in which we have invested.

\section{References}

Books

[1] Security Analysis \& Portfolio Management - Fishers \& Jordon.

[2] Investment analysis and portfolio Management, Chandra, McGraw Hill2009.

[3] Pring Martin J. (1991): Technical Analysis, Explained 'The Successful Investors' Guide to

[4] Spotting Investment Trades and Turning Points, McGraw Hill, 1991.

\section{Research Articles / Report}

[5] Procedia Computer Science 6 (2011) 201-206 Complex Adaptive Systems, Volume 1

[6] Stock Market Prediction with Multiple Regression, Fuzzy Type-2 Clustering and Neural

[7] Networks. David Enkea, Manfred Grauerb, Nijat Mehdiyevb

[8] IJMBS Vol. 1, Issue 1, March 2011 Technical Analysis on Selected Stocks of Energy

[9] Sector R.Chitra.

[10] International Journal of Advanced Research (2013), Volume 1, Issue 4, 430-446

[11] Technical Analysis for Selected Companies of Indian IT Sector - Hemal Pandya

[12] International Journal of Marketing, Financial Services \& Management ResearchVol.2, No. 5,

[13] May (2013) A Study on Fundamental and Technical Analysis, Mr. Suresh A S

\section{Websites}

[14]www.yahoofinance .com

[15] www.google.com

[16] www.wikipedia.com

[17] www.investopedia.com 